\section{What Is the Significance of Change of Cutpoint from 13 to 12 If Polysymptomatic Distress Is Not a Diagnostic Criterion?}

\section{To the Editor:}

Dr. Wolfe, et al reported a new idea about polysymptomatic distress (PSD) ${ }^{1}$. I am afraid that some persons misunderstand that 12 on the PSD scale is a diagnostic criterion for fibromyalgia (FM). He stated that PSD was not a diagnostic criterion ${ }^{2}$. The diagnostic criteria of the 2010 criteria and the modified 2010 criteria for FM are the Widespread Pain Index (WPI) 7 and the Symptom Severity Scale (SSS) 5 or WPI 3-6 and SSS 9 ${ }^{3,4}$. I understand that the PSD scale is useful to evaluate FM severity. If PSD is a diagnostic criterion, change of cutpoint from 13 to 12 has significance. However, PSD is not a diagnostic criterion of FM. The diagnostic criteria are WPI 7 and SSS 5 or WPI 3-6 and SSS 9. What is the significance of the change of cutpoint from 13 to 12 when PSD is not a diagnostic criterion?

The treatment of chronic widespread pain (CWP) and chronic regional pain, incomplete forms of FM, is usually identical with that of FM. This is true for CWP, especially, around the world ${ }^{5}$. Therefore, diagnostic criteria of FM are not clinically useful. If the treatment of 2 or more diseases (or disorders) is the same, it is not clinically useful in distinguishing between diseases (or disorders). I believe that the purpose of the diagnostic criteria is to maintain similar patients in conferences and/or articles. FM, CWP, chronic regional pain, and low back pain are continuum disorders. All diagnostic criteria make incomplete forms of FM. If we consider patients at 5 on the PSD scale (or the number of the tender points is 0 ) as having FM, presentations and articles will cause great confusion. What is the significance of the diagnostic criteria of FM?

Dr. Wolfe, et al stated that FM criteria can be clinically useful ${ }^{1}$. However, in another article, he stated as follows: "Underlying these challenges to FM is the conviction that the FM idea is harmful" ". He showed problems caused by FM (increasing disability, corrupting scientific research, changing psychosomatic illness into compensable disease, etc. $)^{6}$. I often provide an opinion brief for patients with FM after traffic accidents in court. In all likelihood, the insurance companies consisted that the presence of FM is extremely questionable based on his opinion ${ }^{6}$. Sometimes patients with FM after traffic accidents lose a suit in Japan. A few physicians accept the idea of FM in Japan. Some physicians including pain clinicians do not accept the idea of FM in Japan; Wolfe's opinion is one of the reasons. He is a first author of articles that include the diagnostic criteria of $\mathrm{FM}^{3,4,7}$. I am very confused. Could Dr. Wolfe explain the discrepancy?

KATSUHIRO TODA, MD, Rehabilitation, Fukuyama Rehabilitation Hospital. Address correspondence to Dr. K. Toda, Fukuyama

Rehabilitation Hospital, 4-1-15 Miyoshi-chou, Fukuyama-city, Hiroshima

720-0031, Japan.E-mail: goutattack@yahoo.co.jp

\section{REFERENCES}

1. Wolfe F, Walitt BT, Rasker JJ, Katz RS, Häuser W. The use of polysymptomatic distress categories in the evaluation of fibromyalgia (FM) and FM severity. J Rheumatol 2015; 42:1494-501.

2. Toda K. The modification of the American College of Rheumatology preliminary diagnostic criteria for fibromyalgia should be supplemented and revised. J Rheumatol 2011;38:2075; author reply 2076.

3. Wolfe F, Clauw DJ, Fitzcharles MA, Goldenberg DL, Katz RS, Mease P, et al. The American College of Rheumatology preliminary diagnostic criteria for fibromyalgia and measurement of symptom severity. Arthritis Care Res 2010;62:600-10.

4. Wolfe F, Clauw DJ, Fitzcharles MA, Goldenberg DL, Häuser W, Katz RS, et al. Fibromyalgia criteria and severity scales for clinical and epidemiological studies: a modification of the ACR Preliminary Diagnostic Criteria for Fibromyalgia. J Rheumatol 2011;38:1113-22.

5. Toda K. Treatment of chronic widespread pain is similar to treatment of fibromyalgia syndrome throughout the world. J Musculoskelet Pain 2010;18:317-18.

6. Wolfe F. Fibromyalgia wars. J Rheumatol 2009;36:671-8.

7. Wolfe F, Smythe HA, Yunus MB, Bennett RM, Bombardier C, Goldenberg DL, et al. The American College of Rheumatology 1990 Criteria for the Classification of Fibromyalgia. Report of the Multicenter Criteria Committee. Arthritis Rheum 1990;33:160-72.

J Rheumatol 2016;43:2; doi:10.3899/jrheum.150861 